\title{
PENANAMAN NILAI KARAKTER REMAJA MELALUI PERMAINAN TRADISIONAL
}

\author{
Ery Wati $^{1}$, Nurdiana ${ }^{2}$ \\ Program Studi Pendidikan Pancasila Dan Kewarganegaraan (PPkN) \\ Erywati996@gmail.com
}

\begin{abstract}
ABSTRAK
Remaja adalah penerus bangsa yang harus kita persiapkan segala kebutuhannya baik jasmani maupun rohani. Menjadi penerus bangsa yang handal tidak hanya dituntut ilmu yang tinggi atau ketrampilan yang luar biasa akan tetapi bagaimana menciptakan penerus bangsa Indonesia yang berkarakter?. Penanaman karakter saat ini sangat penting dan mendesak karena penggaruh kemajuan era globalisasi yang menawarkan banyak keunggulan yang juga memberikan dampak negative. Manusia cenderung memilih untuk hidup secara individual dan lebih mementingkan dirinya sendiri dan material. Kurangnya komumikasi dengan sesama akan menyebabkan seseorang sulit berinteraksi. Penanaman karakter pada remaja dapat dilakukan melalui permainan tradisional, hal ini sudah pernah dilakukan penelitian oleh Misbach (2006) dari Universitas Pendidikan Indonesia yang berjudul "Peran Permainan Tradisional Yang Bermuatan Educatif Dalam menyumbang Pembentukan Karakter dan Identitas Bangsa"Kesimpulan beliau adalah "Permainan tradisional memiliki peran yang sangat penting dam pembentukkan karakter dan identitas bangsa, permainan tradisional banyak menyumpang karakter-karakter dan kearifan local yang menjadi pandangan hidup suku bangsa dimana karakter tersebut saat ini mulai luntur sedikit demi sedikit".

Atas alasan inilah peneliti sangat tertarik untuk melalukan penelitian tentang "Peranan Permainan Tradisional Aceh Dalam Pembentukan Karakter Remaja"Lokasi penelitian ini di Mukim Sungai Limpah,kecamatan Sukamakmur. Aceh Besar..Penelitian ini bertujuan nuntuk mengetahui faktor yang menyebabkan permainan tradisional aceh hilang dan menggambarkan nilai-nila permainan tradisional dalam membangun karakter remaja. Penelitian ini menggunakan pendekatan deskriptif dan metode kualitatif. Dengan teknik pengumpulan data dokumentasi, observasi dan wawancara. Subjek dalm penelitian ini adalah remaja yang tingkat pendidikannya pada Sekolah Menengah Pertama.Analisis data dilakukan dengan cara reduksi data, penyajian data dan menarik kesimpulan. Dari hasil penelitian yang menyebab permainan tradisional hilang karena kurangnya sosialisasi dari orang tua, padatnya jam sekolah dan kemajuan teknologi dan karakter yang tertanam dalam permainan tradisional tersebut adalah kejujuran,keberanian \, kerjasama, patuh pada aturan dan tenggang rasa
\end{abstract}

Kata Kunci: Permainan Tradisional dan Karakter Remaja

\begin{abstract}
Teenagers are the successor of the nation that we must prepare all their needs both physically and spiritually. Becoming a reliable national successor is not only demanded by high knowledge or extraordinary skills but how to create a successor of the nation of Indonesia with character ?. The cultivation of character nowadays is very important and urgent because the influence of the progress of the globalization era offers many advantages which also have a negative impact. Humans tend to choose to live individually and are more selfish and material. Lack of
\end{abstract}


communication with others will make someone difficult to interact. Cultivation of characters in adolescents can be done through traditional games, this has been done by Misbach (2006) of the Indonesian University of Education entitled "The Role of Educative Traditional Games in Contributing to Forming Nation Character and Identity" His conclusion was "Traditional games have a role which is very important and the formation of national character and identity, many traditional games overlap with local characters and wisdom which become the view of the life of the tribe where these characters are starting to fade little by little "

For this reason researchers are very interested in conducting research on "The Role of Traditional Aceh Games in Forming Youth Character" The location of this study is in Mukim Sungai L abundant, Sukamakmur district. Aceh Besar ... This research aims to find out the factors that cause the traditional games of Aceh to disappear and illustrate the values of traditional games in building teenage characters. This research uses a descriptive approach and qualitative methods. With the technique of collecting data documentation, observation and interviews. The subject of this research is teenagers whose level of education is in junior high school. Data analysis is done by data reduction, data presentation and drawing conclusions. From the results of research that causes traditional games to be lost due to lack of socialization from parents, tight school hours and technological advancements and the characters embedded in these traditional games are honesty, courage, cooperation, obedience to rules and tolerance

Keywords ; Traditional Game and a teenager Characters.

\section{PENDAHULUAN \\ Latar Belakang}

Remaja adalah penerus bangsa yang harus kita persiapkan segala kebutuhannya baik jasmani maupun rohani. Menjadi penerus bangsa yang handal tidak hanya dituntut ilmu yang tinggi atau ketrampilan yang luar biasa akan tetapi bagaimana menciptakan penerus bangsa Indonesia yang berkarakter?.Yang mampu menjawab pertanyaan ini adalah orangtua, pendidik dan lingkungan.

Pada masa remaja awal terjadi kematangan secara kognitif yaitu interaksi dari struktur otak yang telah sempurna dan lingkungan sosial yang semakin luas yang memugkinkan remaja untuk berfikir abstrak. Menurut Yusuf (2007 : 184) masa remaja ini meliputi (a) remaja awal: 12-15 tahun; (b) remaja madya: 15-18 tahun, dan (c) remaja akhir: 19-22 tahun. Pada usia remaja inilah berkembang sifat, sikap dan perilaku yang selalu ingin tahu, merasakan dan ingin mencoba hal-hal baru. Sikap dan perilaku tersebut harus di arahkan atau difasilitasi agar tidak berdampak negative.
Permainan tradisional yang semakin hari senakin hilang ditelan arus perkembangan zaman, menyimpan keunikan, kesenian dan nilai moral. Nilai tersebut hendaknya ditransformasikan kepada generasi muda untuk membangun kepribadian yang berkarakter .Nilai merupakan suatu bobot atau kualitas perbuatan kebaikan yang terdapat dalam segala hal yang dianggap sesuatu yang berharga, berguna dan memiliki manfaat.

$$
\text { Menurut Musbikin }
$$

(2006:45)

"Permainan tradisional tidak hanya bersifat rekreasi atau bersenang-senang saja, permainan tradisional memiliki arti tersendiri dalam menanamkan sikap ,prilaku dan ketrampilan pada remaja. Ada nilai-nilai luhur yang terkandung didalamnya seperti nilai agama,edukatif, norma dan etika yang semua akan bermanfaat bagi remaja ketika terjun dalam kehidupan di masyarakat kelak. Permainan tradisional membuat remaja akan kuat secara fisik, mental, sosial dan emosional, tak mudah menyerah, bereksplorasi, bereksperimen dan menumbuhkan jiwa kepemimpinan". 
Penanaman karakter saat ini sangat penting dan mendesak karena penggaruh kemajuan era globalisasi yang menawarkan banyak keunggulan yang juga memberikan dampak negative. Manusia cenderung memilih untuk hidup secara individual dan lebih mementingkan dirinya sendiri dan material.

Kurangnya komumikasi dengan sesama akan menyebabkan seseorang sulit berinteraksi. Penanaman karakter pada remaja dapat dilakukan melalui permainan tradisional, hal ini sudah pernah dilakukan penelitian oleh Misbach (2006) dari Universitas Pendidikan Indonesia yang berjudul "Peran Permainan Tradisional Yang Bermuatan Educatif Dalam menyumbang Pembentukan Karakter dan Identitas Bangsa"Kesimpulan beliau adalah "Permainan tradisional memiliki peran yang sangat penting dam pembentukkan karakter dan identitas bangsa, permainan tradisional banyak menyumpang karakter-karakter dan kearifan local yang menjadi pandangan hidup suku bangsa dimana karakter tersebut saat ini mulai luntur sedikit demi sedikit".

Atas alasan inilah peneliti sangat tertarik untuk melalukan penelitian tentang "Peranan Permainan Tradisional Aceh Dalam Pembentukan Karakter Remaja"Lokasi penelitian ini di Mukim Sungai Limpah,kecamatan Sukamakmur. Aceh Besar.

\section{Batasan Penelitian}

Untuk membatasi agar penelitian tidak meluas serta untuk memperoleh gambaran yang jelas maka peneliti memfokuskan Pada permainan tradisional aceh Phet-phet nyeut, tak tak galah dan Taloo yeye dalam pembentukan karakter remaja di Mukim Sungai Limpah kecamatan Sukamakmur Aceh Besar

\section{Rumusan Masalah}

Berdasarkan latar belakang distas, maka yang menjadi rumusan masalah dalam penelitian ini adalah

1. Mengapa remaja jarang memainkan permainan tradisional Aceh Phet-phet nyeut. Tak-tak galah dan taloo yeye di Mukim Sungai Limpah kecamatan Sukamakmur Aceh Besar.

2. Bagaimana peranan permainan tradisional Aceh Phet-phet nyeut. Taktak galah dan taloo yeye dapat membentuk karakter remaja di Mukim Sungai Limpah kecamatan Sukamakmur Aceh Besar.

\section{Tujuan Penelitian}

Berdasarkan dari rumusan masalah dalam penelitian di atas, maka tujuan penelitian ini secara umum adalah:

1. Untuk mengetahui penyebab remaja jarang memainkan permainan tradisional Aceh Aceh Phet-phet nyeut. Tak-tak galah dan taloo yeye di Mukim Sungai Limpah kecamatan Sukamakmur Aceh Besar.

2. Untuk mengetahui peranan permainan tradisional Aceh Phet-phet nyeut. Taktak galah dan taloo yeye dapat membentuk karakter remaja di Mukim Sungai Limpah kecamatan Sukamakmur Aceh Besar

\section{Manfaat Penelitian}

Manfaat dari hasi penelitian ini adalah :

1. Permainan tradisional kembali dilestarikan oleh genberasi penerus bangsa

2. Permainan tradisional dapat dijadikan metode pembelajaran di sekolah dan menjadi ide bagi guru di lembaga sekolah untuk mengembangkan keariban local

3. Artikel ilmiah yang diterbitkan pada jurnal lookal yang mempunyai ISSN atau jurnal nasional tidak terakretasi. 


\section{Metodelogi Penelitian \\ Pendekatan dan Jenis Penelitian}

Penelitian ini merupakan sebuah penelitian deskriptif dengan pendekatan kualitatif. Bogdan dan Taylor dalam Moloeng (2007:4) mendefinisikan penelitian kualitatif sebagai prosedur penelitian yang menghasilkan data deskriptif berupa katakata tertulis atau lisan dari orang-orang dan perilaku yang diamati dari fenomena yang terjadi. Lebih lanjut Moleong (2007:11) mengemukakan bahwa penelitian deskriptif menekankan pada data berupa kata-kata, ambar, dan bukan angka-angka yang disebabkan oleh adanya penerapan metode kualitatif.

\section{Populasi dan Sampel}

Populasi adalah keseluruhan subjek penelitian.Populasi dalam penelitian ini adalah 90 orang remaja. Sampel adalah sebagian atau wakil populasi yang diteliti, berdasarkan pemahaman tersebut sampel pada penelitian ini adalah sebagian atau wakil yang sudah ditentukan, Sampel dalam penelitian ini adalah 36 orang remaja $\backslash$. [erwakilan dari setiap desa.

\section{Tenik Pengumpulkan Data}

Teknik pengumpulan data merupakan langkah yang paling utama dalam penelitian, karena tujuan utama dari penelitian adalah mendapatkan data. menurut Sugiyono (2007:209) bila dilihat dari segi cara atau teknik pengumpulan data, maka teknik pengumpulan data dapat dilakukan dengan observasi, wawancara, angket dan dokumentasi. Namun dalam penelitian ini teknik pengumpulan data yang dilakukan oleh peneliti adalah dengan melalui tiga metode, yaitu:

a) Observasi

Observasi bertujuan untuk mengamati subjek dan objek penelitian, sehingga peneliti dapat memahami kondisi yang sebenarnya. Pengamatan bersifat non- partisipatif, yaitu peneliti berada diluar sistem yang diamati.

b) Wawancara

Esterberg dalam Sugiyono (2007:211), mendefinisikan wawancara sebagai pertemuan dua orang atau lebih untuk bertukar informasi dan ide melalui tanya jawab, sehingga dapat dikonstruksikan makna dalam suatu topik tersebut. Dengan wawancara, maka peneliti akan mengetahui hal-hal yang lebih mendalam tentang informan dalam menginterpretasikan situasi dan fenomena yang terjadi, dimana hal ini tidak bisa ditemukan melalui observasi. Dalam melakukan wawancara, peneliti menyiapkan instrumen penelitian berupa pertanyaan-pertanyaan tertulis untuk diajukan, dan mencatat apa yang dikemukakan oleh informan, oleh karena itu jenis jenis wawancara yang digunakan oleh peneliti termasuk kedalam jenis wawancara terstruktur.

c) Dokumentasi

Dokumen merupakan catatan peristiwa yang sudah berlalu. Dokumen bisa berbentuk tulisan, gambar, atau karyakarya monumental seseorang (Sugiyono, 2007:213). Hasil penelitian dari observasi atau wawancara akan lebih kredibel kalau didukung oleh dokumendokumen yang ada.

\section{HASIL DAN PEMBAHASAN}

Faktor remaja jarang memainkan permainan tradisional Aceh di Mukim Sungai Limpah kecamatan Sukamakmur Aceh Besar.

a) Kurangnya sosilaisasi dari orang tua

Dari beberapa wawancara penulis menemukan kesamaan dalam menjawab pertanyaan yaitu Mengapa permainan tradisional jarang di mainkan oleh remaja sekarang,? Alasannya yang pertama karena orang tua remaja sendiri tidak mau lagi mengajarkan atau mensosialisasikan 
permainan tradisional Aceh tersebut. Hal ini akan menyebabkan hilangnya permainan tradisional.

Alasan selanjutnya karena orang tua menganggap bermain hanya membuangbuang waktu, sebaiknya mereka belajar dan membantu orangtua atau lebih baik anak didalam rumah saja daripada harus bermain bersama teman di luar. Tentu saja pendapat tersebut salah karena dunia remaja masih sangat membutuhkan waktu untuk bermain agar mereka bisa bersosialisasi dan bisa mengekspresikan diri.

Sementara itu Wali Kota Banda Aceh, Aminullah Usman (27 Juli 2019, https://kumparan.com/acehkini/lestarikanpermainan-tradisional-remaja-bpnb-acehgelar-festival-1rYApTo1qOU), mengapresiasi BPNB Balai Pelestarian Nilai Budaya Aceh yang menginisiasi kegiatan bermanfaat tersebut. "Ini salah satu upaya konkret untuk melestarikan budaya nusantara, warisan endatu (nenek moyang) kita," katanya.Menurutnya, di era yang semakin modern saat ini, banyak muncul permainan-permainan canggih didukung teknologi tinggi. Hal ini semakin membuat permainan tradisional tak dikenal lagi oleh remaja Aceh. "Bukannya menolak kemajuan teknologi, namun kita perlu menyadari itu tidak seluruhnya membawa dampak positif bagi tumbuh kembang remaja,dan hal ini tentu cukup mengkhawatirkan bagi kita selaku orangtua," katanya lagi.

b) Padatnya kegiatan sekolah

Dari beberapa hasil wawancara dengan remaja dan orang tua remaja maka peneliti dapat engambil beberapa kesimpulan antara lain :

a. Waktu remaja sudah terlalu padat dengan kegiatan disekolah dari jam 07:45 sampai 16:00 WIB sehingga tidak ada waktu untuk keluarga,

b. Akibat dari padatnya kegiatan sekolah waktu bermain remajapun hilang c. Karena mereka waktunya terlalu panjang disekolah kegiatan belajar mengajipun tidak lagi dilakukan karena sudah terlalu lelah.

Hal distas sesuai dengan yang di kemukakan oleh Menteri Pemberdayaan Perempuan dan Perlindungan Remaja Yohana Yembise (16 Juni 2017 https://cantik.tempo.co/read/885233/jamsekolah-sebaiknya-tak-terlalu-lamaalasannya/full\&view ) mengatakan "jam sekolah sebaiknya tidak terlalu lama agar remaja punya waktu cukup untuk berkumpul dengan keluarganya "Saya rasa delapan jam sudah terlalu lama untuk remaja, kami meminta remaja agar tidak terlalu lama di sekolah sehingga mereka bisa berkumpul bersama keluarga mereka," kata Yohana.Menurut dia, waktu remaja bersama keluarga sangat penting, karena keluarga adalah lembaga utama pembentuk karakter remaja.Dia mengatakan KemePPPA telah merekomendasikan kepada Kementerian Pendidikan dan Kebudayaan agar waktu remaja belajar di sekolah tidak lebih dari lima jam."Kalau terlalu banyak jam belajar di sekolah itu sudah melanggar hak remaja, seperti hak bermain,"

c) Kemajuan teknologi

Bermain merupakan salah satu kebutuhan remaja, sejak ia kecil sampai ia tumbuh menjadi remaja kehidupan seharihari tidak terlepas dari bermain, akan tetapi di zaman era globalisasi ini remaja sangat jarang sekali memainkan permainan tradisional, dimana arus tekhnologi lebih dominan, remaja lebih memilih bermain Gadget. Penggunaan gadget sangat dibutuhkan perhatian orang tua, dimana orang tua harus bersikap bijak dalam memberikan alat komunikasi tersebut, jika digunakan secara bijak maka gadget dapat memberikan dampak yang positif, yaitu sebagai media belajar, tetapi jika penggunaan gadget tidak terkontrol maka 
sangat berdampak negative yaitu pada kondisi kesehatan dan tumbuh kembang remaja.

Hal tersebut diatas sesuai kutipan peneliti ambil dari https://id.theasianparent.com/bahaya-gadgetbagi-anak'Seorang Associate Professor of Paediatrics di Bangkok, Dr. Rawat Sichangsirikarn mengatakan bahwa ponsel memang telah menjadi bagian dari kehidupan sehari-hari. Dengan bantuan gadget, kita dapat memeroleh informasi baru dan berkomunikasi dengan cepat. Namun di sisi lain, mereka punya efek samping yang berbahaya.Dampak tersebut begitu serius ketika para orangtua mengizinkan anak-anak mereka menggunakan teknologi gadget, termasuk ponsel atau tablet untuk jangka waktu yang lama. Hal tersebut akan menimbulkan bahaya gadget bagi anak. Screen time yang berlebihan dapat menimbulkan risiko serius pada kesehatan fisik maupun mental anak. Menggunakan aplikasi yang kurang aman bagi si kecil dan kebebasan akses internet yang tanpa batas juga dapat membahayakan mereka. Misalnya, mereka dapat mengakses jejaring sosial yang berbahaya dan tidak pantas, atau terpapar situs web pornografi atau ancaman pemangsa pedofil".

\section{Bagaimana peranan permainan tradisional Tak-Tak Galah dalam membentuk karakter remaja?}

Dalam kegiatan penelitian ini permainan tak-tak galah dibagi 2 group, lakilaki dan perempuan, Sebelum permainan dimulai permainanpun dimulai, Untuk menentukan regu mana yang berjaga maka para ketua regu melempar koin ke atas, bagian yang di atas dialah team yang main duluan. Permainan ini tujuannya adalah untuk menghadang lawan agar tidak sampai pada garis finis. Beberapa karakter yang dapat terbentuk saat memainkan permainan ini adalah: a) Berbuat jujur, yaitu Jika berada dalam kelompok yang mentas mengakui jika tersentuh lawan atau melewati batas mati. Dan jika berada dalam kelompok jaga garis, tidak berbuat curang dengan keluar dari garis penjagaan.

b) Bertanggungjawab, dengan melakukan tugas jaga garis dengan baik sesuai perannya masing-masing.

c) Kerja keras, dengan berusaha keras menerobos garis-garis yang dijaga lawan untuk mendapatkan nilai dan kemenangan. Kerja keras ditunjukkan kelompok yang sedang jaga garis dengan berusaha mengejar anggota kelompok yang sedang mentas untuk menyentuhnya agar keadaan menjadi berbalik.

d) Percaya diri, karena ketika mulai bermain anak-anak tidak pernah berpikir untuk kalah duluan, mereka yakin terhadap kemampuannya untuk menang dan dengan berani menghadapi lawan dalam permain.

e) Berpikir logis, kritis, kreatif dan inovatif, karena merangsang aktivitas berpikir menentukan strategi untuk menerobos garis penjagaan lawan, melihat situasi dan kondisi mengambil kesempatan, mengecoh lawan dan memikirkan bagaimana cara memperoleh kemenangan tanpa tersentuh penjaga garis.

\section{PENUTUP \\ KESIMPULAN.}

Kegiatan penelitian yang berjudul "Peranan Permainan Tradisional Aceh Dalam Membentuk Karakter Remaja"' yang berlokasi pada Mukim Sungai Limpah Kecamata Sukamakmur, Aceh Besar, yang dimulai pada tanggal 19 Mei 2019 sampai dengan 20 Okteber 2019. Populasi dari penelitian adalah semua remaja yang berusia 12 sampai dengan 15 tahun berjumlah 90 orang, Sementara yang menjadi sampel 
dalam penelitian ini adalah 36 orang. Adapun kesimpulan tersebuat adalah sebagai berikut :

1. Faktor yang menyebabkan permainan tradisional aceh sudah sangat jarang dimainkan lagi oleh para remaja di Mukim Sungai Limpah adalah

a. Kurangnya sosialisasi dari orangtua. Para orang tua remaja di sunggai Limpah beranggapan bahwa anak remaja jaman sekarang tidak mau lagi bermain, mereka lebih suka jalanjalan atau kumpul dengan teman nongkrong di suatu tempat, dan sebagaian orang tua lagi beranggapan kalau bermain hanya buang waktu mendingan di rumah belajar dan bantu orangtua.

b. Padatnya jam sekolah

Padatnya jam sekolah menjadikan anak kehilangan waktu bermain, Pergi sekolah jam 07:00 WIB dan tiba kembali kerumah jam 16:00 WIB. Hal tersebut membawa dampak negative bagi tumbuh kembang remaja secara piskologis, anak cendrung tidak bersosialisa lagi dengan teman sebaya di lingkungan rumahnya.

c. Kemajuan Tekhnologi

Kemajuan teknologi membawa dampak positif dan negative bagi para remaja, Hal yang negative terjadi pada permainan, dimana remaja lebih suka bermain gadget daripada bermain permainan tradisional.

2. Peranan Permainan Tradisional Aceh dalam membentuk Karakter remaja.

a. Remaja bisa belajar bersosialisasi. Permainan dilakukan bersama-sama dengan banyak teman tanpa memandang latar belakang keluarga. Semua remaja akan terlibat aktif dalam permainan tersebut. Remaja belajar bersosialisasi, tenggang rasa, toleransi, dan sebagainya. b. Melatih remaja patuh pada aturan. Dalam permainan ini remaja akan bermain bersama dengan mematuhi peraturan yang telah dibuat bersama. Setiap remaja harus bisa mematuhi dan melaksremajaan semua ketentuan yang telah dirumuskan dan disepakati. Jika aturan yang telah dibuat dipatuhi bersama, permainan akan berjalan dengan lancar dan menyenangkan. Belajar berdiskusi akan suatu masalah Permainan yang dilakukan secara bersama-sama tentu diperlukan kesepakatan bersama pula untuk melakukan hal tersebut. Dalam permainan ini semua pemain harus bisa membuat, menyetujui dan melaksremajaan aturan dalam permainannya. Hal ini dilakukan agar tidak terjadi perselisihan yang akan berujung pada pertengkaran.

c. Percaya diri, karena ketika mulai bermain anak-anak tidak pernah berpikir untuk kalah duluan, mereka yakin terhadap kemampuannya untuk menang dan dengan berani menghadapi lawan dalam permain.

d. Melatih sportivitas remaja. Dalam permainan ini, pemain yang kalah dan menang harus bisa menerima dan melakukan tugasnya masing-masing. Remaja akan belajar bagaimana menerima kekalahan dengan tetap menikmati permainan tersebut.

e. Melatih motorik kasar remaja yang sangat bermanfaat untuk membentuk otot yang padat, fisik yang kuat dan sehat, serta mengembangkan kecerdasan kinestetik remaja. Permainan yang dimainkan dengan lompatan - lompatan ini juga bermanfaat menghindarkan remaja dari resiko mengalami obesitas.

f. Melatih keberanian remaja dan mengasah kemampuannya untuk mengambil keputusan. 
g. Menciptakan emosi positif bagi remaja. Sebab ketika bermain, remaja bergerak, berteriak dan tertawa. Gerakan tawa dan teriakan ini sangat bermanfaat untuk membuat emosi remaja menjadi positif,

h. Moral. Dalam permainan tradisional mengenai konsep menang atau kalah. Namun, menang atau kalah tidak menjadikan para pemainnya bertengkar, mereka belajar untuk bersikap sportif dalam setiap permainan. Dan juga tidak ada yang unggul, karena setiap orang punya kelebihan masing - masing untuk setiap permainan. Hal tersebut meminimalis ego di diri remaja.

\section{SARAN}

Berdasarkan dari hasil penelitian, maka saran yang akan oeneliti sampaikan adalah sebagai berikut:

a. Bagi orang tua haruslah bersikap bijaksana dalam memperlakukan anak remaja yang seharusnya mereka masih membutuhkan kesengan bermain, dan kewajiban orang tualah sebagai orang yang terdekat dengan anak mensosialisasikan permainan tradisional daerah.

b. Permainan tradisional yang kaya akan nilai-nilai moral seharusnya tetap harus dilestarikan jangan sampai hilang.

c. Diharapkan juga kepada orang tua dan kembaga pendidikan (sekolah) untuk dapat mengawasi remaja dalam penggunaan gadget.

\section{DAFTAR PERPUSTAKAAN}

Adhin, Fauzil. 2006. Positive Parenting: Cara-Cara Islami Mengembangkan Karakter Positif Pada Remaja Anda. Bandung
B. Hurlock Elizabeth,2004. Perkembangan Remaja. Jakarta: Gelora Aksara Pratama.

Catron, Carol E. \& Allen, Jan (1999). Early Childhood Curriculum A creativePlay Modell. New Jersey: PrenticeHall

dari https://id.theasianparent.com/bahayagadget-bagi-anak'Seorang Associate Professor of Paediatrics di Bangkok, Dr. Rawat Sichangsirikarn

Desmita, Piskologi Perkembangan, Bandung ;Remaja Rosdakarya, 2006.

Dharma Kesuma, dkk, Pendidikan Karakter Kajian Teori dan Praktik di Sekolah, (Bandung: PT Remaja Rosdakarya, 2012)

https://cantik.tempo.co/read/885233/jamsekolah-sebaiknya-tak-terlalu-lamaalasannya/full\&view $=$ ok

https://kumparan.com/acehkini/lestarikanpermainan-tradisional-remaja-bpnbaceh-gelar-festival-1rYApTo1qOU (Okteber 2019)

https://kumparan.com/acehkini/lestarikanpermainan-tradisional-remaja-bpnbaceh-gelar-festival-1rYApTo1qOU),

https://www.membumikanpendidikan.com/2 015/03/kebutuhan-bermain-padaremaja-dan.html

Imam Musbikin, Mendidik Anak Kreatif Ala Einstein, Yogyakarta; Mitra Pusaka 2006

M.Mahbubi, Pendidikan Karakter Implementasi Aswaja sebagai Nilai Pendidikan Karakter, (Yogyakarta: Pustaka Ilmu, 2012), 
Jurnal Sains Riset (JSR)

ISSN 2088-0952

Misbach. I.H (2006. Peran Permainan Tradisional Yang Bermuatan Edicatif Dalam Menyumbang Pembentukan Karakter Dan Identitas Bangsa. Diakses 10 Juli 2018 dari http: /file.upi.edu/direktori/fip/jur.piskolog i/197507292005012ifa_hanifah_misb ach/laporan_penelitian_peran_permai nan-tradisional_revisi_final.pdf

Munandar, Utami S.C. (1992). Mengembangkan Bakat dan Kreativitas Remaja Sekolah. Jakarta : PT Grasindo
Semiawan, Conny. R. 2002. Belajar dan Pembelajaran dalam Taraf Usia Dini. Jakarta: PT Ikrar Mandiri Abad

Sofyan S. Willis. (2005). Remaja dan Masalahnya Mengupas Berbagai bentuk Kenakalan Remaja seperti Narkoba, Freesex dan Pemecahannya. Bandung: $\quad \mathrm{CV}$ Alfabeta.

Yusuf Syamsu. (2004). Psikologi Remaja dan Rema 